\title{
Estrogens downregulate urocortin 2 expression in rat uterus
}

\section{Kenichiro Watanabe ${ }^{1,2}$, Takahiro Nemoto ${ }^{2}$, Shigeo Akira', Toshiyuki Takeshita' and Tamotsu Shibasaki ${ }^{2}$}

Departments of ${ }^{1}$ Obstetrics and Gynecology and ${ }^{2}$ Physiology, Nippon Medical School, 1-1-5 Sendagi, Bunkyo-ku, Tokyo 113-8602, Japan
Correspondence should be addressed to T Nemoto

Email

taknemo@nms.ac.jp

\begin{abstract}
Urocortin 2 (Ucn2) is a member of the corticotropin-releasing factor peptide family and is expressed by various tissues, including reproductive tissues such as the uterus, ovary, and placenta. However, the regulatory mechanisms of Ucn2 expression and the physiological significance of Ucn2 in these tissues remain unclear. We previously showed that passive immunization of immature female rats by i.p. injection of anti-Ucn $2 \mathrm{lg}$ induces earlier onset of puberty. Therefore, this study was designed to clarify the site and regulatory mechanisms of Ucn2 expression in the uterus. Expression levels of Ucn2 mRNA in the uterus were higher in immature (2- and 4-week-old) and aged (17-month-old) rats than in mature (9-week-old) rats in the proestrus phase. In 9-week-old rats, mRNA expression levels and contents in the uterus were lower in the proestrus phase than in the diestrus phase, while plasma Ucn2 concentrations did not differ between the two phases. Ucn2-like immunoreactivitiy was detected in the endometrial gland epithelial cells of the uterus. S.c. injection of estradiol benzoate or an estrogen receptor $\alpha(E R \alpha)$ agonist significantly reduced mRNA expression levels and contents of Ucn2 in the uterus when compared with vehicle-injected ovariectomized rats. By contrast, estradiol benzoate increased Ucn2 mRNA expression levels in the lung. Thus, estrogens downregulate Ucn2 expression in the uterus in a tissue-specific manner, and Ucn2 may play a role in the regulatory mechanisms of maturation of the uterus through ER $\alpha$ and estrous cycle.
\end{abstract}
Key Words
- estrogen
- urocortin 2
uterus
- estrous cycle

\section{Introduction}

Corticotropin-releasing factor (CRF) has a variety of physiological roles in the endocrine system, autonomic nervous system, mood, behavior, and gastrointestinal system under stress (Bale \& Vale 2004, Heinrichs \& Koob 2004, Smith \& Vale 2006). Urocortin 2 (Ucn2) is a member of the CRF peptide family, which acts through binding to CRF type 2 receptor (CRF-R2). Others and we previously demonstrated that Ucn 2 is expressed in both the brain and peripheral tissues, including the lung, adrenal, uterus, ovary, and testis (Hsu \& Hsueh 2001, Yamauchi et al. 2005, Lee et al. 2011). It has been reported that expression of
Ucn2 mRNA in various tissues is controlled by stress, inflammation, and hypoxia (Tanaka et al. 2003, Tao et al. 2006, Chang et al. 2007, Buhler et al. 2009, Imperatore et al. 2010, Nemoto et al. 2010) and that factors involved in the regulation of Ucn2 mRNA expression are CRF, glucocorticoids, and endotoxins (Chen et al. 2003, 2004, Tanaka et al. 2003, Chang et al. 2007, Nemoto et al. 2007, Yuan et al. 2012). Ucn2 mRNA is strongly expressed in the uterus during the proliferative phase in healthy women, and the expression is abolished in patients with endometriosis (Novembri et al. 2011). However, the regulatory 
mechanisms of Ucn2 expression in reproductive organs are not well understood.

Estrogens regulate many physiological processes in both the reproductive system and the cardiovascular systems, metabolism, behavior, and mood. In the uterus, estrogens trigger the precisely timed physiological and biochemical responses required for establishing the menstrual cycle and maintaining pregnancy. The effects of estrogens are mediated by receptors in large part through the regulation of gene transcription, and estrogen receptors (ERs) are involved in either activating or repressing transcription of target genes. It has not been studied whether and how the expression of Ucn2 in the uterus is influenced by estrogens. In this study, we therefore studied the influences of age, estrous phase, ovariectomy (OVX), and estrogen administration on Ucn2 mRNA expression levels and contents in the uterus, as well as plasma Ucn2 concentrations, of female rats.

\section{Materials and methods}

\section{Animals}

Female Wistar rats were maintained at $23 \pm 2{ }^{\circ} \mathrm{C}$ on a $12 \mathrm{~h}$ light: $12 \mathrm{~h}$ darkness cycle (lights on at $0800 \mathrm{~h}$, off at $2000 \mathrm{~h}$ ). They were allowed ad libitum access to laboratory chow and distilled water. Estrous cycle of rats was determined by vaginal impedance measurements using an MK-10C (Muromachi Kikai Co. Ltd, Tokyo, Japan) and vaginal cytological findings and was confirmed by measuring plasma estrogen concentrations. All experimental procedures were reviewed and approved by the Laboratory Animals Ethics Committee of Nippon Medical School.

\section{Ovariectomized and estrogen administration}

Forty-two female rats underwent bilateral OVX through a dorsal approach or sham surgery under sodium pentobarbital anesthesia $(5 \mathrm{mg} / \mathrm{kg}$ body weight, i.p.). After surgery, all rats were housed in their home cages and allowed a week of recovery. For estrogen replacement, $2 \mu$ g estradiol benzoate (Sigma Chem. Co.) dissolved in $0.5 \mathrm{ml}$ sesame oil were injected s.c. into OVX rats at $0930 \mathrm{~h}$. An ER $\alpha$-specific agonist propylpyrazoletriol (PPT; Tocris Bioscience, Minneapolis, MN, USA) and an ER $\beta$ agonist diarylpropionitrile (DPN; Tocris Bioscience) were dissolved in dimethyl sulfoxide (DMSO), and $2.5 \mathrm{mg} / \mathrm{kg}$ body weight of PPT or DPN was injected s.c. into OVX rats at $0930 \mathrm{~h}$. The dose of estradiol benzoate elicits maximum plasma estradiol concentrations that appear to be in the proestrus range (Kuriyama \& Shibasaki 2004), and doses of PPT and DPN were determined based on previous studies (Asl et al. 2013).

\section{Plasma estradiol assay}

Rats were decapitated and trunk blood was collected into tubes containing EDTA $2 \mathrm{Na}(1 \mathrm{mg} / \mathrm{ml}$ blood $)$ followed by centrifugation at $3000 \boldsymbol{g}$ for $20 \mathrm{~min}$ at $4{ }^{\circ} \mathrm{C}$. Blood samples from two 2-week-old rats were pooled for assays because the amount of blood obtained from one 2-week-old animal was small. A $1 \mathrm{ml}$ aliquot of plasma was transferred into $1.5 \mathrm{ml}$ Eppendorf tubes and stored at $-80^{\circ} \mathrm{C}$ for later measurement. Plasma $17 \beta$-estradiol and Ucn 2 concentrations were measured using an estradiol EIA kit (Cayman Chemical Company, Ann Arbor, MI, USA).

\section{Tissue and plasma Ucn2 assay}

Fifteen of 2-week-old, ten of 4-week-old, 32 of 9-week-old, and five of 17-month-old rats were used. Two to five uteri from each experimental group were pooled and analyzed as one sample because contents of Ucn2 were too small for analysis. Uteri were weighed, homogenized in 15-fold extract buffer solution (PBS contained 0.2\% Nonidet P-40), and centrifuged at $10000 \mathrm{~g}$ for $20 \mathrm{~min}$ at $4{ }^{\circ} \mathrm{C}$. One milliliter of each plasma was mixed with $2 \mu \mathrm{l}$ Nonidet P-40 and centrifuged at $10000 \mathrm{~g}$ for $20 \mathrm{~min}$ at $4{ }^{\circ} \mathrm{C}$. Supernatants of tissue or plasma samples were moved to an HLB 3cc Extraction Cartridge (Waters, Milford, MA, USA), pretreated with $6 \mathrm{ml}$ ethanol, followed by rinsing with $6 \mathrm{ml}$ distilled water. Columns were washed with $6 \mathrm{ml}$ distilled water, and Ucn2 was eluted using $2 \mathrm{ml}$ acetonitrile containing $0.075 \%$ TFA solution. Eluates were evaporated to dryness using a centrifugal evaporator. Samples were dissolved in $200 \mu \mathrm{l}$ buffered solution (provided from Rat Urocortin 2 EIA kit, Yanaihara Institute, Inc., Shizuoka, Japan). Tissue Ucn2 contents and plasma Ucn 2 concentrations were assayed using a Rat Ucn2 EIA kit (Yanaihara Institute, Inc.) in accordance with the manufacturers' protocol and data were corrected by uterine weight or plasma volume respectively.

\section{RNA extraction and real-time RT-PCR analysis}

Rats were decapitated, their uteri were removed, and total RNA was extracted using Isogen II (Nippon Gene, Tokyo, Japan). First-strand cDNA was synthesized using $0.5 \mu \mathrm{g}$ denatured total RNA at $37^{\circ} \mathrm{C}$ for $15 \mathrm{~min}, 84^{\circ} \mathrm{C}$ for $5 \mathrm{~s}$, and

Published by Bioscientifica Ltd 
$4{ }^{\circ} \mathrm{C}$ for 5 min using a PrimeScript RT reagent kit (Takara, Shiga, Japan). PCR was performed by denaturation at $94^{\circ} \mathrm{C}$ for $5 \mathrm{~s}$ and annealing-extension at $60^{\circ} \mathrm{C}$ for $30 \mathrm{~s}$ for 40 cycles, using SYBR premix Ex Taq (Takara) and specific primers for rat Ucn2 (GenBank number: NM_13385, forward primer: GAGCAACTCTAAAGCCAGCCCTTAC and reverse primer: TGATTCCTGGCAGCCTTGTTC) and GAPDH (GenBank number: NM_017008, forward primer: GGCACAGTCAAGGCTGAGAATG and reverse primer: ATGGTGGTGAAGACGCCAGTA). To normalize each sample for RNA content, GAPDH, a housekeeping gene, was used. Diluted uterine cDNA and the second-derivative method (Nolan et al. 2006) were used to calculate Ct values respectively.

\section{Immunohistochemistry}

Female Wistar rats were anesthetized with pentobarbital (50 mg/kg body weight by i.p. injection) and perfused via an intracardiac cannula with PBS followed by $4 \%$ paraformaldehyde. The uterus was removed, left overnight in $4 \%$ paraformaldehyde, and was then transferred to $20 \%$ sucrose/PBS. Tissues were sectioned at $10 \mu \mathrm{m}$ using a cryostat, collected onto poly L-lysine-coated slides, and air-dried.

Sections were incubated with the specific polyclonal antiserum against Ucn2 (1:1000) (Yamauchi et al. 2005) for overnight at $4{ }^{\circ} \mathrm{C}$. Tissues were rinsed in PBS and incubated in biotinylated goat anti-rabbit IgG (1:200, Vector Laboratories, Burlingame, CA, USA) for $1 \mathrm{~h}$ at room temperature. This was followed by another $1-\mathrm{h}$ incubation in avidin-biotin complex solution (Vectorstain ABC Elite kit, Vector Laboratories) at room temperature. The antibody-peroxidase complex was visualized using diaminobenzidine (Vector DAB kit; Vector Laboratories). When staining had reached appropriate intensity, tissue was rinsed in PBS and then tissue was counterstained with methyl green. After rinsed with pure water, tissue was dehydrated through a graded alcohol series, cleared in xylene, and coverslipped with VectaMount (Vector Laboratories). To test the specificity of staining, antiUcn 2 serum preincubated with $10 \mu \mathrm{g}$ rat Ucn 2 was used in the experiments. These treatments did not affect the intensity of staining. Preincubation of anti-Ucn2 serum with $10 \mu \mathrm{g}$ rat Ucn 2 completely abolished the staining.

\section{Western blotting of CRF-R2}

The uterine tissues were lysed with TNE buffer $(10 \mathrm{mM}$ Tris-HCl, $\mathrm{pH} 7.8,1 \% \mathrm{NP}-40,150 \mathrm{mM} \mathrm{NaCl}$, and $1 \mathrm{mM}$ EDTA) containing the Complete proteinase inhibitor cocktail (Roche Diagnostics). Lysates were subjected to centrifugation to remove debris and the protein
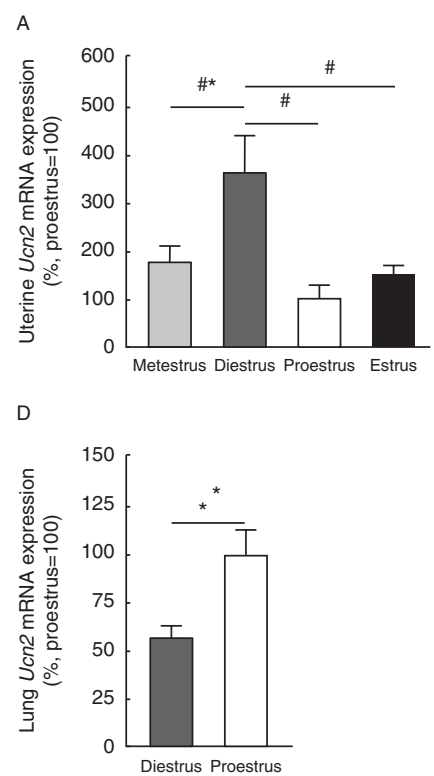

B
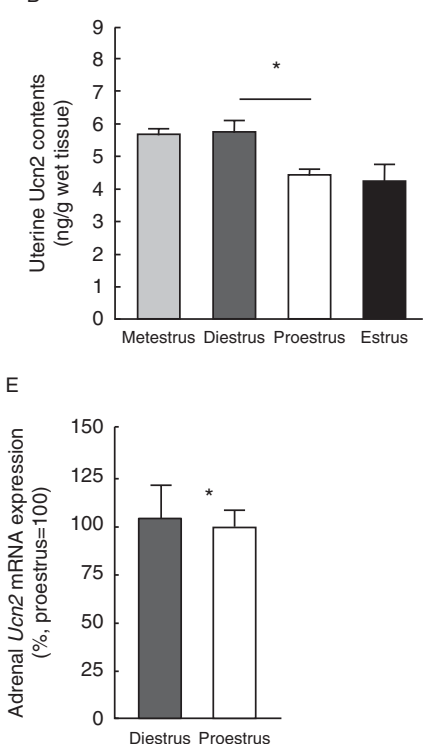

C

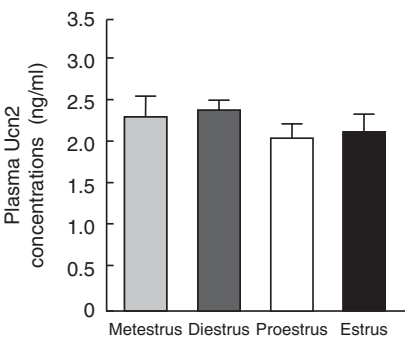

$\mathrm{F}$

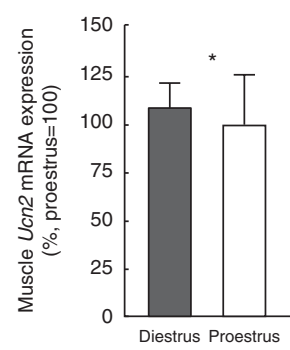

\section{Figure 1}

Ucn2 mRNA expression levels and contents during estrous cycle of 9-week-old female rats. Uterine (A), lung (D), adrenal (E) and muscle (F) Ucn2 mRNA, peptide contents (B), and plasma concentrations (C) were assayed during the estrous cycle of 9-week-old female rats.
mRNA expression levels are shown as a percentage of those in rats in the proestrus phase. Values are expressed as the means \pm s.E.M. $P$ values of $<0.05$ were considered to be significant. ${ }^{\#} P<0.01$ vs diestrus, ${ }^{\star} P<0.05$ vs proestrus. $n=8$. http://joe.endocrinology-journals.org DOI: $10.1530 / J O E-13-0228$
(C) 2013 Society for Endocrinology Printed in Great Britain 
concentrations in each supernatant were measured. Each sample of protein extract $(20 \mu \mathrm{g})$ was mixed with $3 \times$ SDS sample buffer (200 mM Tris-HCl, pH 6.8, 30\% glycerol, $6 \%$ SDS, $0.03 \%$ bromophenol blue, and 3\% $\beta$-mercaptoethanol); each mixture was then boiled for $5 \mathrm{~min}$. Proteins in each sample were then separated by SDS-PAGE and transferred onto PVDF membranes. The membranes were blocked with $10 \%$ nonfat dried milk and incubated with goat anti-CRF-R2 antibody (N-20, sc-1826, Santa Cruz Biotechnologies) (1:200). The membranes were washed and then incubated with HRP-conjugated anti-goat IgG (Jackson Immuno Research Laboratory, West Grove, PA, USA). ChemiDoc XRS (Bio-Rad Laboratories, Inc.) and SuperSignal West Dura Extended Duration Substrate (Thermo Scientific, Rockford, IL, USA) were used to detect and measure CRF-R2 immunoreactive signal. After detecting CRF-R2 signal, each membrane was incubated in restore PLUS western blot stripping buffer (Thermo Scientific) to remove the antibodies. The membrane was reprimed with mouse anti- $\beta$-actin, MAB (Progen Biotechnik, Heidelberg, Germany), and then incubated with HRP-conjugated anti-mouse-IgG (Jackson Immuno Research Laboratory). The $\beta$-actin immunoreactive signals were detected and measured to normalize for equal loading and blotting efficiency.

\section{Statistical analysis}

Statistical analysis was performed using two-way ANOVA and an unpaired $t$-test using Prism 6.0 software (GraphPad Software, Inc., La Jolla, CA, USA). For real-time RT-PCR data, all results were expressed as a percentage of control levels. Statistical significance was established at the $P<0.05$ level.

\section{Results}

\section{Comparison of mRNA expression levels and contents of Ucn2 in each estrous phase}

Plasma estrogen concentrations in the metestrus, diestrus, proestrus, and estrus phases were $13.4 \pm 1.1,19.3 \pm 2.6$, $29.9 \pm 2.8$, and $13.8 \pm 1.1 \mathrm{pg} / \mathrm{ml}$ (mean \pm s.E.M., $n=6$ ) respectively and those in the proestrus phase were significantly higher than those in the other three phases $(P<0.0001$ vs metestrus, $P<0.01$ vs diestrus, and $P<0.0001$ vs estrus). Expression level of Ucn 2 mRNA in the uterus of proestrus phase was the lowest among other phases. The expression levels of Ucn 2 mRNA were significantly higher in the diestrus than in the proestrus phase $(3.6 \pm 0.8$-fold of proestrus, $n=8, P<0.01)$ in the uterus (Fig. 1A). Ucn2 contents in the uterus in the proestrus phases were significantly lower than those in the diestrus phase $(4.4 \pm 0.2 \mathrm{ng} / \mathrm{g}$ wet tissue for proestrus and $5.7 \pm 0.4 \mathrm{ng} / \mathrm{g}$ wet tissue for diestrus, $n=8, P<0.05$ ) (Fig. 1B), while there were no significant differences in
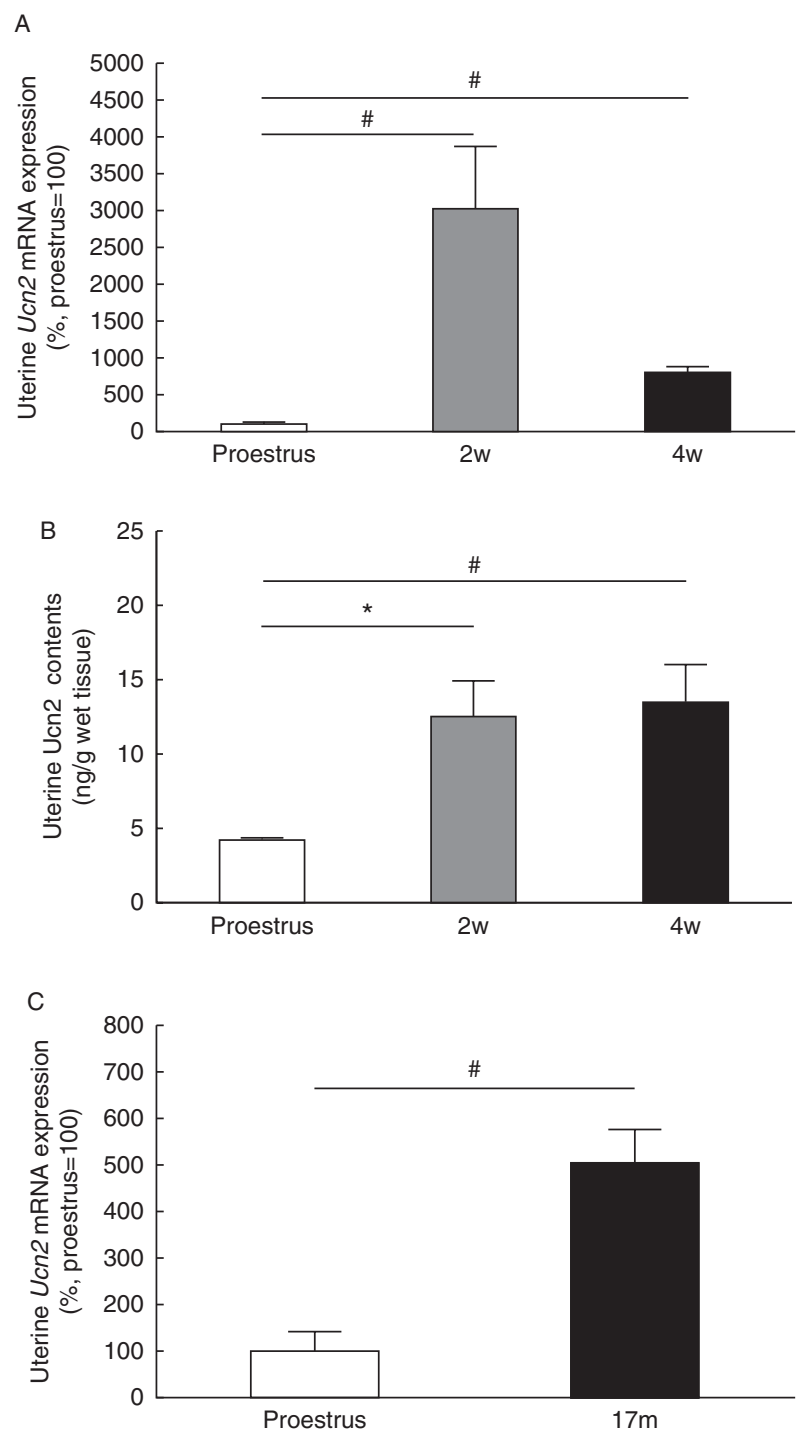

Figure 2

Ucn2 mRNA expression levels and contents in uterus of 2- and 4-week-old immature female rats, 9-week-old rats in the proestrus phase, and 17month-old female rats. Uterine Ucn2 mRNA expression (A and C) and contents (B) were assayed in 2- and 4-week-old immature female rats, 9 -week-old female rats in the proestrus phase, and 17-month-old postmenopausal female rats. Uterus samples were pooled and extracted for Ucn2 EIA assay. mRNA expression levels are shown as a percentage of those in 9-week-old rats in the proestrus phase $(n=8)$. Values are expressed as the means \pm S.E.M. $P$ values of $<0.05$ were considered to be significant. ${ }^{\#} P<0.001$ vs proestrus, ${ }^{\star} P<0.01$ vs proestrus. 
plasma Ucn2 concentrations among each estrous phase (Fig. 1C). The expression levels of Ucn2 mRNA in the lung were significantly higher in the proestrus phase than in the diestrus phase $(1.8 \pm 0.3$-fold of diestrus, $n=8$, $P<0.05$ ) (Fig. 1D).

\section{Ucn2 mRNA and contents in uterus in 2-, 4- and 9-week and 17-month-old female rats}

Plasma estrogen concentrations of 2- and 4-week-old immature female rats, 9-week-old mature female rats in the proestrus phase, and 17-month-old rats were $10.4 \pm$ $0.7,9.8 \pm 1.1,29.9 \pm 2.8$, and $7.3 \pm 1.0 \mathrm{pg} / \mathrm{ml}$ respectively. The expression levels of Ucn 2 mRNA in the uterus were significantly higher in 2- and 4-week-old rats than in 9-week-old rats in the proestrus phase $(30.2 \pm 8.5$ - and $8.0 \pm 8.3$-fold of proestrus of 9-week-old rats respectively, $n=8, P<0.001$ ) (Fig. 2A). The contents of Ucn2 in the uterus were significantly higher in 2 - and 4 -week-old rats
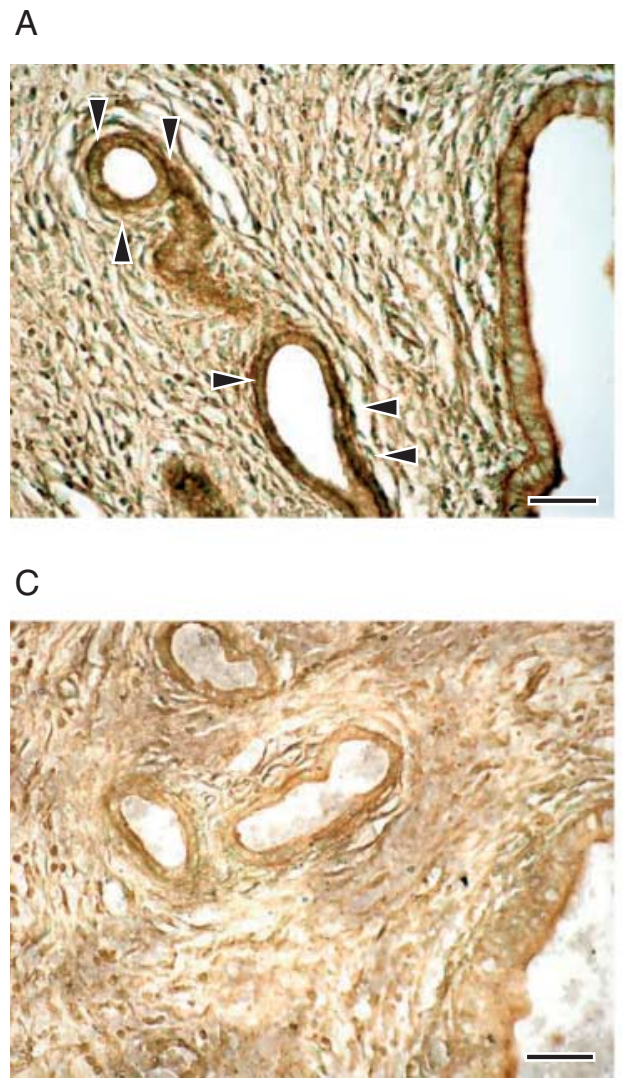

Figure 3

Localization of Ucn2 in the uterus of 9-week-old female rats at diestrus and proestrus phases. Ucn2-like immunoreactivity was observed in the endometrial gland endothelial cells in the proestrus (A) and diestrus (B) when compared with 9-week-old rats in the proestrus phase $(12.5 \pm 2.4 \mathrm{ng} / \mathrm{g}$ wet tissue for 2 -week-old rats $(P<0.01), 13.5 \pm 2.5 \mathrm{ng} / \mathrm{g}$ wet tissue for 4 -week-old rats $(P<0.001)$, and $4.2 \pm 0.2 \mathrm{ng} / \mathrm{g}$ wet tissue for 9-week-old rats at proestrus phase) (Fig. 2B). Similarly, expression level of Ucn2 mRNA in the uterus of 17-month-old rats was significantly higher than that in 9-week-old rats in the proestrus phase (5.0 \pm 0.7 -fold 9-week-old rats at proestrus phase, $P<0.001$ ) (Fig. 2C).

\section{Localization of Ucn2 in uterus}

Ucn2-like immunoreactivity (LI) was detected in the endometrial gland epithelial cells of the uterus (Fig. 3A and $\mathrm{B}$ ), although the signal densities in the diestrus phase did not differ from those in the proestrus phase. Ucn2-LI in the diestrus or proestrus phase was abolished by preincubation of anti-Ucn2 antibody with $10 \mu \mathrm{g}$ Ucn2 (Fig. 3C and D).
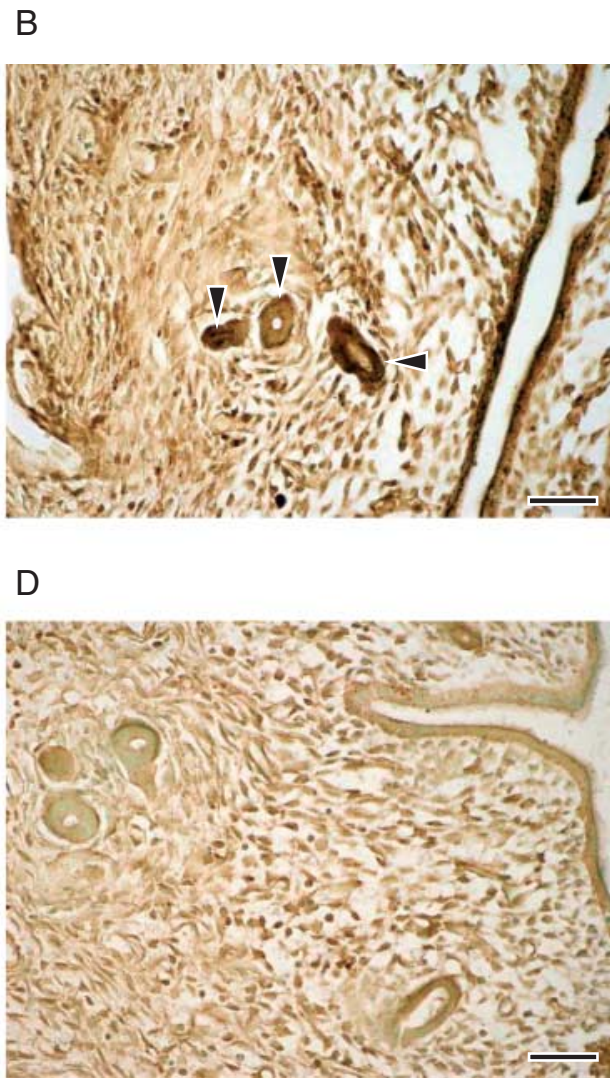

phases. Signals were abolished by preincubation of anti-Ucn 2 antisera with $10 \mu \mathrm{g}$ of rat Ucn2 in the diestrus (C) and proestrus (D) phases. Arrowheads indicate endometrium gland epithelial cells. Scale bar $=50 \mu \mathrm{m}$.

Published by Bioscientifica Ltd. 


\section{Administration of estradiol benzoate decreased mRNA and content of Ucn2 in uterus of OVX rats}

Plasma estrogen concentrations were undetectable in both estradiol benzoate- and vehicle-administered OVX rats. Twenty-four and $48 \mathrm{~h}$ after s.c. administration of estradiol benzoate, expression levels of Ucn 2 mRNA $(4.2 \pm 1.0 \%$ for $24 \mathrm{~h}$ and $4.6 \pm 1.2 \%$ for $48 \mathrm{~h}$ vs vehicle-administered control respectively, $n=6, P<0.01$, Fig. 4A) and Ucn2 contents $(5.6 \pm 0.4 \mathrm{vs}$ vehicle, $8.6 \pm 1.3 \mathrm{ng} / \mathrm{g}$ wet tissue for $24 \mathrm{~h}(P<0.01), 6.3 \pm 1.0$ vs vehicle, $11.0 \pm 0.7 \mathrm{ng} / \mathrm{g}$ wet tissue for $48 \mathrm{~h}(P<0.001), n=6$, Fig. $4 \mathrm{~B})$ were significantly lowered when compared with vehicle-administered controls in the uterus of OVX rats, while there were no significant differences in plasma Ucn2 concentrations between the groups at 24 and $48 \mathrm{~h}$ after sample administration (Fig. 4C). Twenty-four hours after s.c. administration of estradiol benzoate, the expression levels of Ucn 2 mRNA in the lung were significantly higher than those of vehicle-administered OVX rats $(2.9 \pm 0.3$-fold of vehicle-administered control, $n=6, P<0.001$, Fig. 4D) with no changes in Ucn 2 mRNA expression in the adrenal gland (Fig. 4E) or in the skeletal muscle (Fig. 4F).

\section{ER $\alpha$ agonist decreased mRNA expression levels and peptide contents of Ucn2 in uterus of OVX rats}

Twenty-four hours after s.c. administration of each ER agonist, plasma estrogen concentrations were undetectable in each ER agonist- and vehicle-administered OVX rats. An ER $\alpha$ agonist, PPT, significantly decreased Ucn2 mRNA $(69.7 \pm 7.9 \%$ of vehicle administration, $n=8$, $P<0.01$, Fig. 5A) and Ucn 2 contents $(9.4 \pm 0.6 \mathrm{ng} / \mathrm{g}$ wet tissue for PPT administration vs $17.9 \pm 1.1 \mathrm{ng} / \mathrm{g}$ wet tissue
A

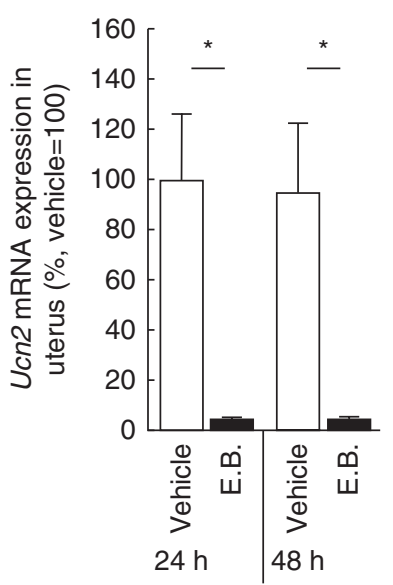

D

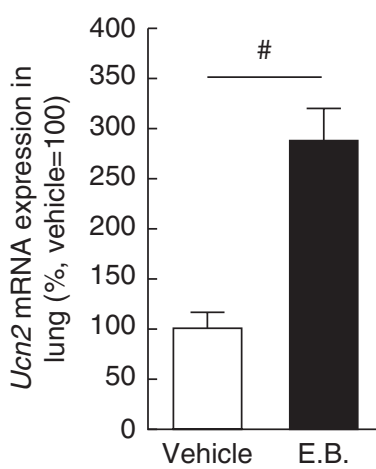

B

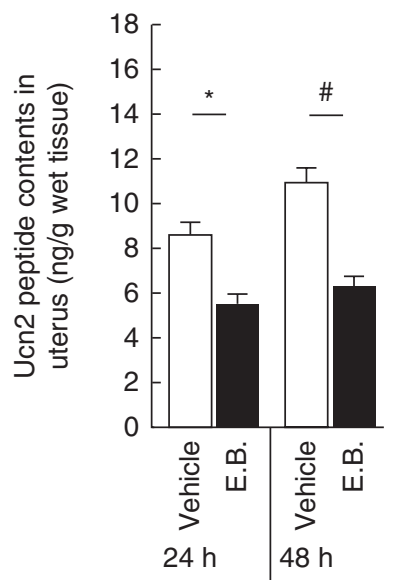

E

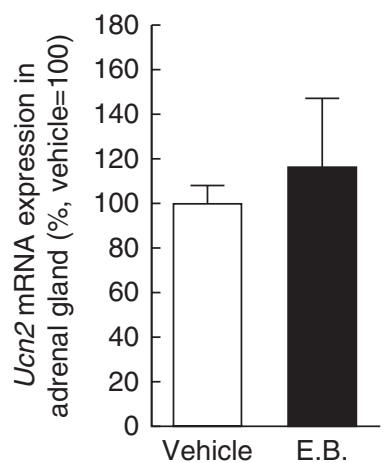

C

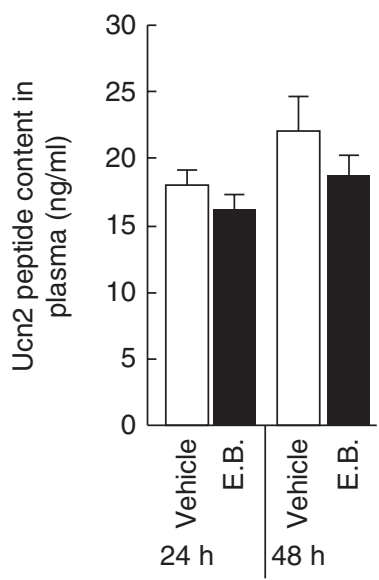

$\mathrm{F}$

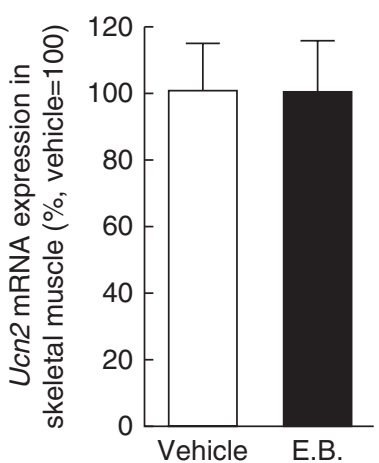

Figure 4

Effects of estrogen administration on uterine Ucn2 mRNA expression levels and contents and plasma Ucn2 concentrations in OVX rats. Uterine Ucn2 mRNA expression levels (A), contents (B), and plasma Ucn2 concentrations (C) were assayed at $24-$ and $48 \mathrm{~h}$ after s.c. administration of $2 \mu \mathrm{g}$ estradiol benzoate or vehicle. Ucn2 mRNA expression levels in the lung (D), adrenal
(C) 2013 Society for Endocrinology Printed in Great Britain gland (E) and muscle (F) were assayed at 24-h after s.c. administration of estradiol benzoate or vehicle. mRNA expression levels are shown as a percentage of those in vehicle-injected rats. EB, estradiol benzoate. Values are expressed as the means \pm S.E.M. $P$ values of $<0.05$ were considered to be significant. ${ }^{*} P<0.01$ and ${ }^{\#} P<0.001$ vs vehicle control. $n=6$. 

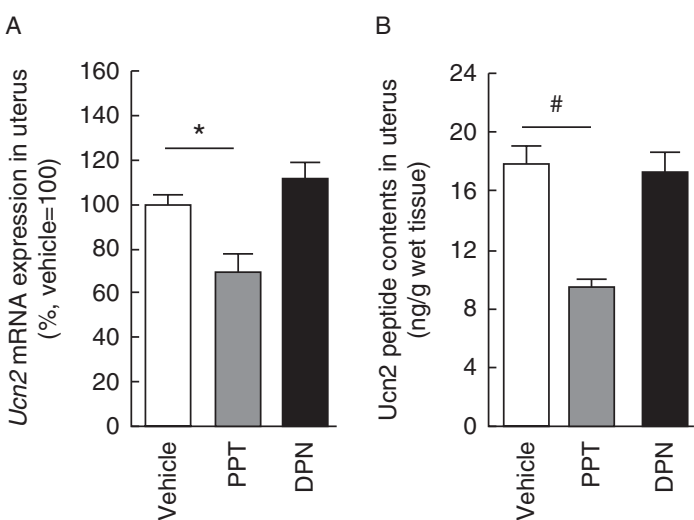

Figure 5

Effect of ER $\alpha$ or $\beta$ agonist on Ucn2 mRNA expression and tissue content of uterus and lung of OVX rats. mRNA expression levels ( $A$ for uterus and $C$ for lung) and peptide contents ( $B$ for uterus and $D$ for lung) of Ucn2 were assayed at $24 \mathrm{~h}$ after s.c. administration of $2.5 \mathrm{mg}$ PPT, an ER $\alpha$ agonist, DPN,

for vehicle administration, $n=8, P<0.001$, Fig. 5B), while an ER $\beta$ agonist, DPN, did not show significant changes in the expression levels and peptide contents of Ucn2 in uterus of OVX rats (Fig. 5A and B). By contrast, DPN slightly but significantly increased Ucn2 mRNA expression levels $(1.06 \pm 0.01$-fold of vehicle administration, $n=8$, $P<0.01$, Fig. 5C) without affecting in its peptide contents (Fig. 5D) in the lung, while PPT showed no significant changes in mRNA expression levels (Fig. 5C) or peptide contents of $U c n 2$ (Fig. 5D) in the lung of OVX rats.

\section{Expression levels of CRF-R2 mRNA and protein in uterus of proestrus rats, diestrus rats, and estradiol benzoate- administered OVX rats}

Expressions of CRF-R2 mRNA and protein in the uterus of diestrus rats were significantly higher than those of proestrus rats $(1.1 \pm 0.02$-fold of proestrus for mRNA expression and $1.3 \pm 0.1$-fold of proestrus for protein expression, $n=8, P<0.05$, Fig. $6 \mathrm{~A}, \mathrm{~B}$, and C). Estradiol benzoate administration in OVX rats did not change the expression of CRF-R2 mRNA or protein in the uterus (Fig. 6D, E, and F).

\section{Discussion}

We have previously shown that Ucn2 mRNA is strongly expressed in reproductive tissues including the uterus (Yamauchi et al. 2005). In this study, Ucn2-LI was detected in endometrial gland epithelial cells of the uterus in rats.
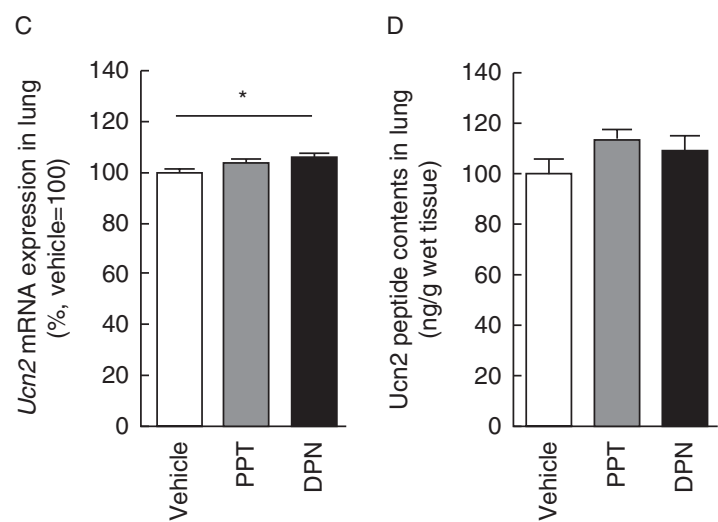

an ER $\beta$ agonist, or vehicle. mRNA expression levels are shown as a percentage of those in vehicle-injected rats. Values are expressed as the means \pm s.E.M. $P$ values of $<0.05$ were considered to be significant. ${ }^{*} P<0.01$ and ${ }^{\#} P<0.001$ vs vehicle control. $n=6$.

We also showed that Ucn2 mRNA expression levels and contents in the uterus were higher in immature and aged female rats than in mature female rats in the proestrus phase; plasma estradiol concentrations in the two former groups were significantly lower than those in the latter group. Ucn 2 mRNA expression levels and contents in the uterus of mature rats were significantly higher in the diestrus phase than those in the proestrus phase, while plasma estrogen concentrations were significantly lower in the diestrus phase than in the proestrus phase. These results are consistent with a previous human study showing that endometrial Ucn2 mRNA levels show peak in the early proliferative phase (Novembri et al. 2011). Furthermore, we demonstrated that estradiol benzoate or ER $\alpha$ agonist, but not ER $\beta$ agonist, significantly decreases Ucn 2 mRNA expression levels and contents in the uterus of OVX rats. Taken together, this suggests that Ucn2 is negatively regulated by estrogens through $\mathrm{ER} \alpha$.

In this study, we also found that estradiol benzoate administration increased Ucn2 mRNA expression in the lung without changing in the skeletal muscle and adrenal gland, in contrast to the suppressive effects on Ucn2 expression in the uterus. Previous studies demonstrated that glucocorticoids alter Ucn2 mRNA expression in various tissues in a tissue- or cell-specific manner (Chen et al. 2003, 2004). Thus, estrogen-induced modification of Ucn2 mRNA expression also occurs in a tissue- or cellspecific manner. We were unable to perform Ucn2 promoter assay because the rat Ucn2 promoter has not been identified yet and we were unable to identify it. 
A

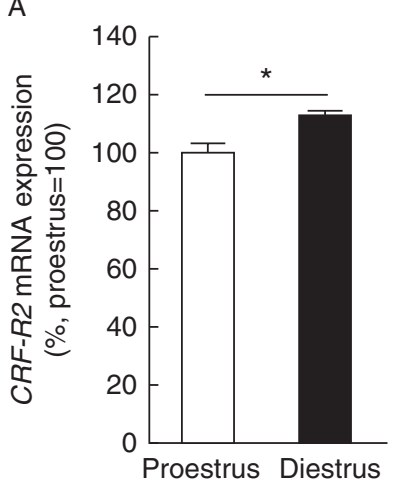

C

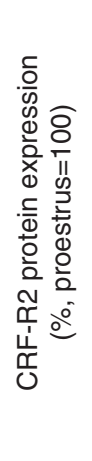

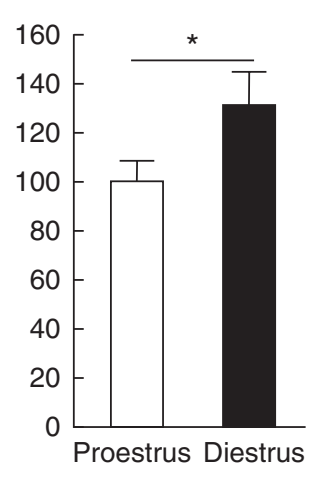

B

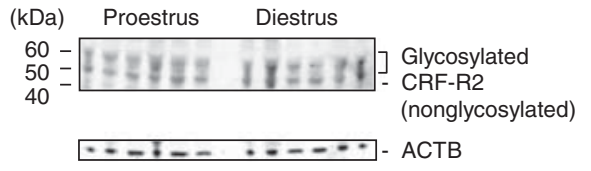

Figure 6

CRF-R2 mRNA and protein expression levels during estrous cycle of intact rats and after estrogen administration in OVX rats. mRNA ( $A$ and $D$ ) and protein (B, C, E, and F) expression of CRF-R2 in the uterus were assayed during the estrous cycle of 9-week-old female rats $(A, B$, and $C)$, or $2 \mu \mathrm{g}$ estradiol benzoate- or vehicle-administered OVX rats (D, E, and F).

Database analysis suggests that there are several half palindrome estrogen-responsive elements in the $5^{\prime}$-site of the Ucn2 gene. As there may be multiple mechanisms involved in estrogen-induced gene repression, further studies are needed to clarify the mechanisms underlying estrogen-induced repression of Ucn2 mRNA expression. On the other hand, ER $\beta$ agonist-induced increase in Ucn2 mRNA expression was very small in the lung of OVX rats, and no change in Ucn2 mRNA expression was induced in the lung of OVX rats by ER $\alpha$ agonist. Therefore, the major mediator through which estrogens increase Ucn2 mRNA expression in the lung is not ER $\beta$.

Although we have previously shown that secretion of Ucn2 from the anterior pituitary is regulated by CRF and dexamethasone (Nemoto et al. 2007), the details of the regulatory mechanisms of Ucn 2 secretion from peripheral tissues are unknown. The mRNA expression levels and contents of Ucn2 in uterus were decreased in estradiol benzoate-administered OVX rats, as shown in this study. However, this study also showed that Ucn 2 contents in the uterus did not change in parallel with mRNA expression during estrous phase or during aging. It therefore seems likely that the regulatory mechanisms of Ucn2 secretion from the uterus are not necessarily estrogen dependent. Taken together, these results suggest that factors other than estrogens are involved in the mechanisms underlying Ucn2 secretion from the uterus in rats.
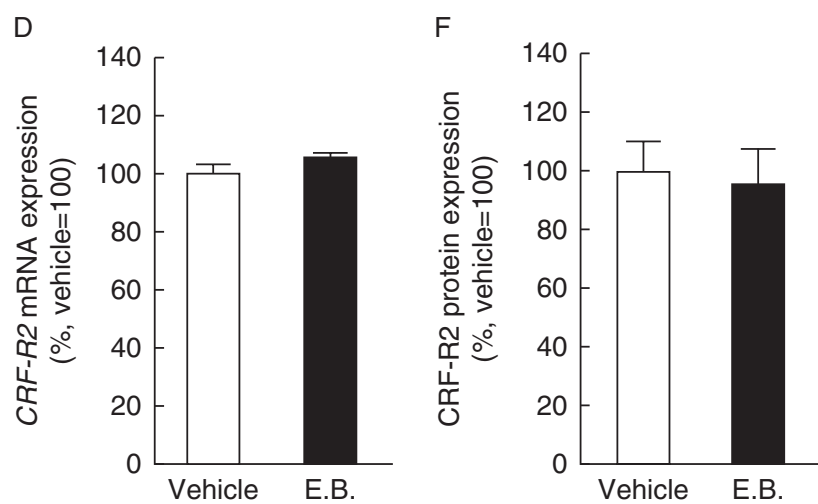

E

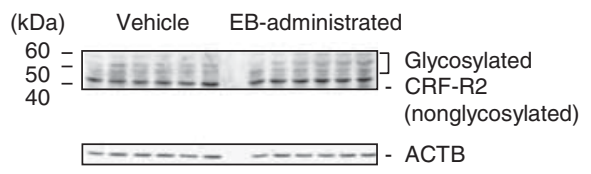

The mRNA and protein expressions of CRF-R2 are shown as a percentage of those in rats in the proestrus phase or in vehicle-administered rats. Values are expressed as the means \pm s.E.M. $P$ values of $<0.05$ were considered to be significant. ${ }^{*} P<0.05$ vs proestrus or vehicle. $n=8$.

The role of Ucn2 secreted from the uterus remains unclear. It has been reported that Ucn2 and other members of CRF family peptides delay gastric emptying, and their expression is induced by lipopolysaccharide injection in rats (Czimmer et al. 2006, Yuan et al. 2012); Ucn2 inhibits the hypoxia-induced apoptosis in mesenteric arterial smooth muscle cells from spontaneously hypertensive rats (Tao et al. 2006), and i.v. injection of Ucn2 increases plasma angiotensin II and noradrenaline concentrations, cardiac output, heart rate and left ventricular ejection fraction, and renin activity in healthy humans (Davis et al. 2007). However, plasma Ucn2 concentrations are not significantly affected by age differences, estrous phase, or estrogen administration in female rats as shown in this study. We have previously demonstrated that the amount of Ucn2 secreted from rat anterior pituitary cells is $\sim 1 / 40$ of that of ACTH (Nemoto et al. 2007) and that Ucn 2 has a paracrine tonic and inhibitory effect on gonadotropin (Nemoto et al. 2009). We found that expressions of CRF-R2 mRNA and protein in the uterus of diestrus rats were higher than those of proestrus rats. However, estradiol benzoate treatment did not significantly change the expression of CRF-R2 mRNA and protein compared with that of vehicle treatment in OVX rats. These results therefore suggest that the expressions of CRF-R2 mRNA and protein in the uterus may be independent of estrogens. Further studies are

Published by Bioscientifica Ltd 
necessary in order to clarify the regulatory mechanisms underlying CRF-R2 expression in the uterus. It has been reported that Ucn2-LI is present in human placenta, amnion, and chorion and that the concentrations of Ucn2 in placenta are 1/50 of those of CRF (Pepels et al. 2009). Moreover, a previous study using knockout mice showed that Ucn2 is a local negative regulator of glucose uptake in skeletal muscle (Chen et al. 2006). These results suggest that uterine Ucn2 plays a paracrine role. Furthermore, our previous study showed that daily passive immunization of immature female rats with an i.p. injection of anti-Ucn2 IgG induces earlier onset of puberty. It has been reported that estrogen release and P450 aromatase mRNA expression are enhanced in the presence of Ucn2 in cultured human trophoblast cells (Imperatore et al. 2009). Taken together with these results, this study suggests that the uterine Ucn2/CRF-R2 system may cross talk with the estrogen system and may have regulatory roles in the estrous cycle and/or reproductive events.

\section{Declaration of interest}

The authors declare that there is no conflict of interest that could be perceived as prejudicing the impartiality of the research reported.

\section{Funding}

This study was supported in part by grants for Research on Measures for Intractable Diseases, Health and Labor Sciences Research Grants from the Ministry of Health, Labor, Ministry of Education, Culture, Sports, Science and Technology (MEXT)-supported program for the Strategic Research Foundation at Private Universities, 2008-2012, and JSPS KAKENHI Grant Numbers 23791238 (2011-2013) and 24592490 (2012-2014).

\section{References}

Asl SZ, Khaksari M, Khachki AS, Shahrokhi N \& Nourizade S 2013 Contribution of estrogen receptors alpha and beta in the brain response to traumatic brain injury. Journal of Neurosurgery 119 353-361. (doi:10.3171/2013.4.JNS121636)

Bale TL \& Vale WW 2004 CRF and CRF receptors: role in stress responsivity and other behaviors. Annual Review of Pharmacology and Toxicology 44 525-557. (doi:10.1146/annurev.pharmtox.44.101802. 121410)

Buhler K, Plaisance I, Dieterle T \& Brink M 2009 The human urocortin 2 gene is regulated by hypoxia: identification of a hypoxia-responsive element in the 3'-flanking region. Biochemical Journal 424 119-127. (doi:10.1042/BJ20090311)

Chang J, Hoy JJ, Idumalla PS, Clifton MS, Pecoraro NC \& Bhargava A 2007 Urocortin 2 expression in the rat gastrointestinal tract under basal conditions and in chemical colitis. Peptides 28 1453-1460. (doi:10.1016/j.peptides.2007.05.008)

Chen A, Vaughan J \& Vale WW 2003 Glucocorticoids regulate the expression of the mouse urocortin II gene: a putative connection between the corticotropin-releasing factor receptor pathways. Molecular Endocrinology 17 1622-1639. (doi:10.1210/me.2003-0054)

Chen A, Blount A, Vaughan J, Brar B \& Vale W 2004 Urocortin II gene is highly expressed in mouse skin and skeletal muscle tissues: localization, basal expression in corticotropin-releasing factor receptor (CRFR) 1- and CRFR2-null mice, and regulation by glucocorticoids. Endocrinology 145 2445-2457. (doi:10.1210/ en.2003-1570)

Chen A, Brar B, Choi CS, Rousso D, Vaughan J, Kuperman Y, Kim SN, Donaldson C, Smith SM, Jamieson P et al. 2006 Urocortin 2 modulates glucose utilization and insulin sensitivity in skeletal muscle. PNAS 103 16580-16585. (doi:10.1073/pnas.0607337103)

Czimmer J, Million M \& Tache Y 2006 Urocortin 2 acts centrally to delay gastric emptying through sympathetic pathways while CRF and urocortin 1 inhibitory actions are vagal dependent in rats. American Journal of Physiology. Gastrointestinal and Liver Physiology 290 G511-G518. (doi:10.1152/ajpgi.00289.2005)

Davis ME, Pemberton CJ, Yandle TG, Fisher SF, Lainchbury JG, Frampton CM, Rademaker MT \& Richards AM 2007 Urocortin 2 infusion in healthy humans: hemodynamic, neurohormonal, and renal responses. Journal of the American College of Cardiology 49 461-471. (doi:10.1016/j.jacc.2006.09.035)

Heinrichs SC \& Koob GF 2004 Corticotropin-releasing factor in brain: a role in activation, arousal, and affect regulation. Journal of Pharmacology and Experimental Therapeutics 311 427-440. (doi:10.1124/ jpet.103.052092)

Hsu SY \& Hsueh AJ 2001 Human stresscopin and stresscopin-related peptide are selective ligands for the type 2 corticotropinreleasing hormone receptor. Nature Medicine 7 605-611. (doi:10.1038/87936)

Imperatore A, Li W, Petraglia F \& Challis JR 2009 Urocortin 2 stimulates estradiol secretion from cultured human placental cells: an effect mediated by the type 2 corticotrophin-releasing hormone (CRH) receptor. Reproductive Sciences 16 551-558. (doi:10.1177/ 1933719109332830)

Imperatore A, Rolfo A, Petraglia F, Challis JR \& Caniggia I 2010 Hypoxia and preeclampsia: increased expression of urocortin 2 and urocortin 3. Reproductive Sciences 17 833-843. (doi:10.1177/ 1933719110373147)

Kuriyama H \& Shibasaki T 2004 Sexual differentiation of the effects of emotional stress on food intake in rats. Neuroscience 124 459-465. (doi:10.1016/j.neuroscience.2003.12.012)

Lee S, Braden B, Kang SS \& Rivier C 2011 Urocortins are present in the rat testis. Neuropeptides 45 131-137. (doi:10.1016/j.npep. 2010.12.006)

Nemoto T, Iwasaki-Sekino A, Yamauchi N \& Shibasaki T 2007 Regulation of the expression and secretion of urocortin 2 in rat pituitary. Journal of Endocrinology 192 443-452. (doi:10.1677/joe.1.07023)

Nemoto T, Yamauchi N \& Shibasaki T 2009 Novel action of pituitary urocortin 2 in the regulation of expression and secretion of gonadotropins. Journal of Endocrinology 201 105-114. (doi:10.1677/ JOE-08-0467)

Nemoto T, Iwasaki-Sekino A, Yamauchi N \& Shibasaki T 2010 Role of urocortin 2 secreted by the pituitary in the stress-induced suppression of luteinizing hormone secretion in rats. American Journal of Physiology. Endocrinology and Metabolism 299 E567-E575. (doi:10.1152/ajpendo. 00163.2010)

Nolan T, Hands RE \& Bustin SA 2006 Quantification of mRNA using real-time RT-PCR. Nature Protocols 1 1559-1582. (doi:10.1038/ nprot.2006.236)

Novembri R, Carrarelli P, Toti P, Rocha AL, Borges LE, Reis FM, Piomboni P, Florio P \& Petraglia F 2011 Urocortin 2 and urocortin 3 in endometriosis: evidence for a possible role in inflammatory response. Molecular Human Reproduction 17 587-593. (doi:10.1093/molehr/ gar020) 
Pepels PP, Spaanderman ME, Bulten J, Smits PB, Hermus AR, Lotgering FK \& Sweep CG 2009 Placental urocortins and CRF in late gestation. Placenta 30 483-490. (doi:10.1016/j.placenta.2009.03.008)

Smith SM \& Vale WW 2006 The role of the hypothalamic-pituitaryadrenal axis in neuroendocrine responses to stress. Dialogues in Clinical Neuroscience 8 383-395.

Tanaka Y, Makino S, Noguchi T, Tamura K, Kaneda T \& Hashimoto K 2003 Effect of stress and adrenalectomy on urocortin II mRNA expression in the hypothalamic paraventricular nucleus of the rat. Neuroendocrinology 78 1-11. (doi:10.1159/000071700)

Tao J, Zhang Y, Soong TW \& Li S 2006 Urocortin II inhibits the apoptosis of mesenteric arterial smooth muscle cells via
L-type calcium channels in spontaneously hypertensive rats. Cellular Physiology and Biochemistry 17 111-120. (doi:10.1159/ 000092072)

Yamauchi N, Otagiri A, Nemoto T, Sekino A, Oono H, Kato I, Yanaihara C \& Shibasaki T 2005 Distribution of urocortin 2 in various tissues of the rat. Journal of Neuroendocrinology 17 656-663. (doi:10.1111/j.1365-2826. 2005.01354.x)

Yuan PQ, Wu SV \& Tache Y 2012 Urocortins and CRF type 2 receptor isoforms expression in the rat stomach are regulated by endotoxin: role in the modulation of delayed gastric emptying. American Journal of Physiology. Gastrointestinal and Liver Physiology 303 G20-G31. (doi:10.1152/ajpgi.00547.2011)

Received in final form 5 October 2013 Accepted 9 October 2013

Accepted Preprint published online 9 October 2013
Published by Bioscientifica Ltd. 